NIST Special Publication 1223

\title{
Technical Review of NIST's Free Standard Reference Data Products
}

\author{
Debra L. Kaiser \\ Robert J. Hanisch
}

This publication is available free of charge from:

https://doi.org/10.6028/NIST.SP.1223

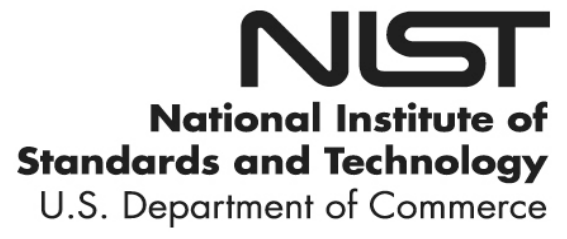


NIST Special Publication 1223

\title{
Technical Review of NIST's Free Standard Reference Data Products
}

\author{
Debra L. Kaiser \\ Material Measurement Laboratory Office \\ Material Measurement Laboratory
}

Robert J. Hanisch

Office of Data and Informatics Material Measurement Laboratory

This publication is available free of charge from:

https://doi.org/10.6028/NIST.SP.1223

April 2018

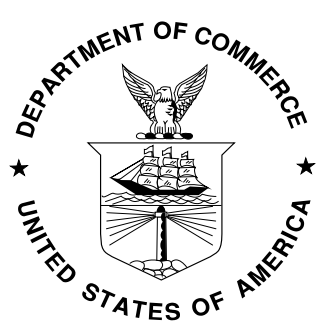

U.S. Department of Commerce Wilbur L. Ross, Jr., Secretary

National Institute of Standards and Technology Walter Copan, NIST Director and Under Secretary of Commerce for Standards and Technology 
Certain commercial entities, equipment, or materials may be identified in this document in order to describe an experimental procedure or concept adequately. Such identification is not intended to imply recommendation or endorsement by the National Institute of Standards and Technology, nor is it intended to imply that the entities, materials, or equipment are necessarily the best available for the purpose.

\title{
National Institute of Standards and Technology Special Publication 1223 Natl. Inst. Stand. Technol. Spec. Publ. 1223, 15 pages (April 2018) \\ CODEN: NSPUE2
}

This publication is available free of charge from: https://doi.org/10.6028/NIST.SP.1223

\section{Foreword}

The Material Measurement Laboratory (MML) has responsibility for the NIST-wide Standard Reference Data (SRD) Program, and the Office of Data and Informatics (ODI) in MML leads, oversees, and manages the SRD Program as one of its many responsibilities. SRDs are a vital component of NIST's standards mission and providing critically evaluated data has contributed substantially to NIST's reputation as a leader in the international standards community.

\begin{abstract}
Over the past two years, the ODI has undertaken an ambitious effort to modernize the SRD Program. This report covers one aspect of this modernization effort, a comprehensive internal technical review of the 75 free data products currently carrying the SRD label. As part of this review, critical evaluation criteria for SRD were developed, and specific evaluation methods used by SRD researchers were compiled. Each of the 75 data products was analyzed for compliance with the criteria and use of the methods, taking into consideration that the 2017 SRD Act Update stipulated data to include digital data objects. The outcome of this analysis was that $65 \%$ of the data products will retain the SRD label. The remaining $35 \%$ of the data products will be assigned to other categories that better describe their content, including data compilations, bibliographic collections, and information resources. This report also includes an analysis of the latest date of new content for all 75 current free data products and a discussion of the implications of this analysis. Planning is underway for an external review of selected SRD Databases and other data products.
\end{abstract}




\section{Table of Contents}

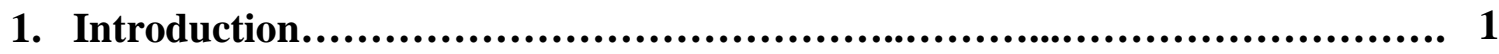

2. Critically Evaluated Data.................................................. 1

3. Current SRD Product Portfolio.................................................. 2

4. Standard Reference Data Program Review.................................... 3

5. SRD Technical Review........................................................ 3

5.1. Self-Assessment Stage................................................... 3

5.2. Internal Review Stage..................................................... 4

5.2.1. Data Product Categories........................................... 6

5.2.2. Latest Date of New Content............................................ 6

5.2.3. Authoritative Data Products............................................. 7

5.3. External Review Stage ................................................... 7

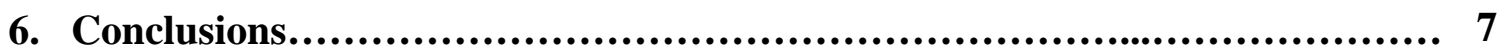

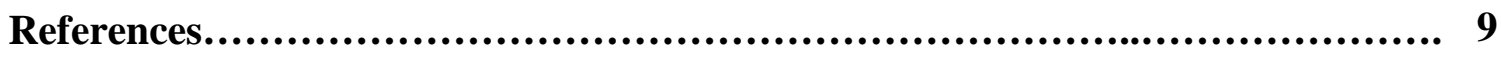

Appendix A: Free Data Product Categories.......................................... 10

\section{List of Tables}

Table 1. Evaluation methods..................................................... 5

\section{List of Figures}

Fig. 1. Number of SRDs by NIST laboratory..................................... 2

Fig. 2. Distribution of SRDs by discipline....................................... 2

Fig. 3. Distribution of technical contact recommendations.......................... 4

Fig. 4. Distribution of reclassified data products.................................... 6

Fig. 5. Latest dates of new content for all free data products........................ 6

Fig. 6. Latest dates of new content for SRDs..................................... 7 


\section{Introduction}

The National Bureau of Standards (NBS) established the Office of Standard Reference Data (SRD) in 1963 to develop a National Standard Reference Data System [1]. The emphasis of the SRD system was the production of compilations of critically evaluated data. Five years later, Congress passed the Standard Reference Data Act [2], a law that authorized and directed the Secretary of the Department of Commerce to provide or arrange for the collection, compilation, critical evaluation, publication, and dissemination of standard reference data. The Act defined SRD as "quantitative information, related to a measurable physical or chemical property of a substance or system of substances of known composition and structure, which is critically evaluated as to its reliability." Appropriations to carry out the SRD Act were authorized in 1969 [3], and funds were provided in fiscal years 1970 and 1971 to formalize the SRD Program, a hallmark of NBS's, and now NIST's, measurement services.

In 2015-2016, the Director of the Office of Data and Informatics (ODI) in the Material Measurement Laboratory (MML) co-led a multi-year effort to expand the scope of SRD. This effort resulted in Section 108, Standard Reference Data Act Update, in Public Law No: 114-329, American Innovation and Competitiveness Act [4]. In this 2017 Update, the term SRD means data that is-

a. either-

i. quantitative information related to a measurable physical, or chemical, or biological property of a substance or system of substances of known composition and structure;

ii. measurable characteristics of a physical artifact or artifacts;

iii. engineering properties or performance characteristics of a system; or

iv. one or more digital data objects that serve-

(a) to calibrate or characterize the performance of a detection or measurement system; or

(b) to interpolate or extrapolate, or both, data described in (i)-(iii); and

b. that is critically evaluated as to its reliability under section 290b of this title.

Digital data objects may include images such as fingerprints or scanned documents, videos, and software.

\section{Critically Evaluated Data}

It is noteworthy that a definition of, or the requirements for, "critically evaluated data” were not specified in the original SRD Act, the SRD Act Update, or any internal NBS or NIST publication. As a result, the authors developed the following definition:

"Critically evaluated data” are assessed by experts and are trustworthy such that people can use the data with confidence and base significant decisions on the data.

For numerical data, the critical evaluation criteria are:

a. Assuring the integrity of the data, such as provision of uncertainty determinations and use of standards;

b. Checking the reasonableness of the data, such as consistency with physical principles and comparison with data obtained by independent methods; and 
c. Assessing the usability of the data, such as inclusion of metadata and well-documented measurement procedures.

For digital data objects, the critical evaluation criteria are:

a. Assuring the object is based on physical principles, fundamental science, and/or widely accepted standard operating procedures for data collection; and

b. Checking for evidence that

i. The object has been tested, and/or

ii. Calculated and experimental data have been quantitatively compared.

\section{Current SRD Product Portfolio}

For simplicity, the acronym SRD will also be taken to mean Standard Reference Database. There are 75 free SRDs accessible on the web and 41 SRDs for sale by NIST as e-commerce transactions, via distributors, downloads, distributor agreements and site licenses, and CDs/DVDs. This report concerns only the free SRDs which are listed in Appendix A in numerical order by assigned SRD number. All content for the free SRDs is available from links on the SRD catalog [5]. Figures 1 and 2 show the numbers of free SRDs by NIST Laboratories and scientific disciplines, respectively.

As expected based on the Laboratories' missions, 97\% of the SRDs are ascribed to the Material Measurement Laboratory (MML) and the Physical Measurement Laboratory (PML). The Engineering Laboratory (EL) and the Information Technology Laboratory (ITL) each have one SRD. As shown in Fig. 2, the SRDs may be classified in five measurement disciplines. Nearly half of the SRDs concern physical properties, followed in decreasing number by chemical, materials, and biological properties.

In addition to SRDs, NIST has produced 14 Special Databases on various subjects (e.g., synthesized documents, fingerprint cards, and PIV cards) and one Special Software product. Ten of these data products are free and five are for sale. Per the 2017 SRD Act Update whereby digital data objects are included, Special Databases and Software products may be labelled as SRDs. Decisions regarding such assignments will be made at a future date.

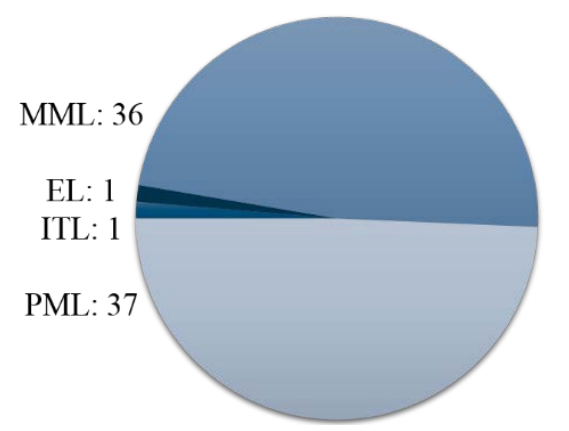

Fig 1. Number of SRDs by NIST Laboratory

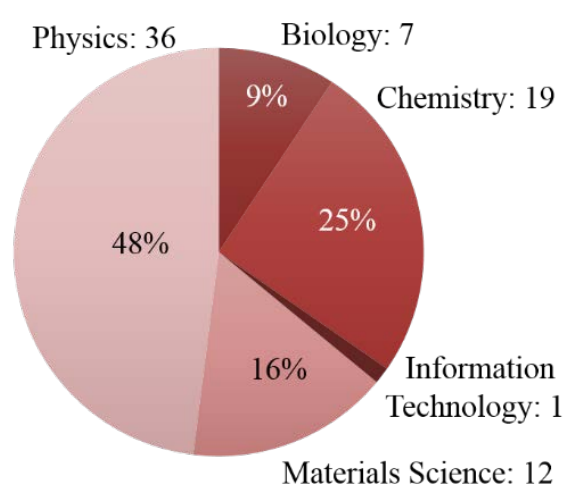

Fig. 2. Distribution of SRDs by discipline 


\section{Standard Reference Data Program Review}

In late 2015, the ODI initiated a comprehensive process to evaluate the SRD Program. An advisory committee of senior staff members ${ }^{1}$ from the NIST Laboratories, Special Programs Office (SPO), Program Coordination Office (PCO), and Office of the Chief Counsel (OCC) was convened to consider modernization of the SRD Program, including web interface redesign, application programming interfaces, and technical content, the subject of this report. Discussions focused on two technical issues: (1) the factors considered in the assignment of SRD numbers to data products over the past 20 years are unclear; and (2) many of SRDs are quite old $-48 \%$ of the free SRDs have not been updated in the past decade. The committee confirmed the importance of the SRD Program and recommended that a comprehensive technical review be performed to address the following issues:

a. Are there SRDs that are incorrectly categorized or retained?

i. Obsolescence of content or function

ii. Inadequate evaluation

iii. Not compliant with the SRD Act

b. Are there Special Databases that should be SRDs?

\section{SRD Technical Review}

Following the recommendations of the committee, the ODI initiated a technical review of the SRD Program. There are four goals of the review:

a. Assure that NIST is delivering the highest quality products and maintaining the NIST SRD "brand" in compliance with the SRD Act Update

b. Identify SRDs of great use and impact that would benefit from updates

c. Discern potential gaps in the SRD program that NIST could or should remedy

d. Understand the technical impact that the SRD program has had for industry, other government agencies, and the academic research community.

Note that the SRD label allows NIST, through the Secretary of Commerce, to hold copyright and, where appropriate, to charge fees for the use of SRD to recover costs of production and distribution.

There are three stages of the technical review: self-assessment by the SRD technical contacts; an internal review; and an external review by subject matter experts. This Special Publication covers the first two stages as pertaining to the first goal.

\subsection{Self-Assessment Stage}

In October 2016, the ODI Director requested the following information from the SRD technical contacts:

a. The SRD number and name

\footnotetext{
${ }^{1}$ John Curry, PML; Kirk Dohne, EL; Heather Evans, Program Coordination Office; Carlos Gonzalez, MML; Chris Greer, EL; Barbara Guttman, ITL; Stephanie Hooker, MML; Thomas O’Brian, PML; Marc Salit, MML; Hratch Semerjian, MML Associate; Katherine Sharpless, Special Programs Office, James Whetstone, Special Programs Office; Carl Williams, PML; and Henry Wixon, Office of the Chief Counsel (who was sometimes represented by Mark Madsen).
} 
b. The approximate date of latest revision

c. How the data were critically evaluated (no guidance was provided)

d. The state of the SRD from a software perspective, e.g., language, operating system dependencies, web presence

e. Recommendation for disposition

i. Keep as SRD and proceed to a peer review stage

ii. Keep as SRD but add documentation to note current limitations or appropriate use cases

iii. Keep as SRD if resources can be found to update and revise

iv. Retain data but remove from SRD category

v. Retire altogether, e.g., data are obsolete, better data are available elsewhere

The technical contacts' recommendations for the 75 free SRDs in (i)-(iv) above, referred to hereafter as "data products", are provided in Appendix A. For these data products, the number of responses for the first four recommended dispositions are presented in Fig. 3. In the few cases where the technical contact did not specify a recommendation, one was assigned in the internal review process.

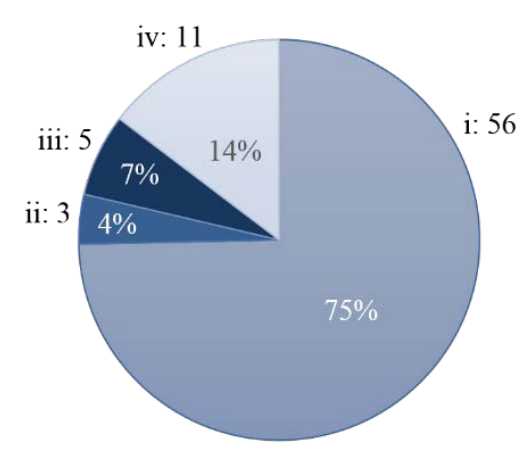

Fig. 3. Distribution of technical contact recommendations

\subsection{Internal Review Stage}

An internal review of the free data products was conducted by the authors. This section describes the process by which this review addressed the first goal given above-assure that NIST is delivering the highest quality products and maintaining the NIST SRD "brand" in compliance with the SRD Act Update. A first key step was to validate the technical contact information for each data product which exists in a database maintained by the ODI. This was accomplished via the self-assessment responses and additional correspondence with NIST staff members and associates. In some cases, the original technical contacts had changed their status (e.g., reassigned or left NIST) and new contacts were designated. It should be noted that the catalog of SRDs [5] includes all the data products identified during the internal review.

It became apparent in early 2017 that the information from the self-assessment exercise was not sufficient to address the issues raised by the 2015 SRD advisory committee. Consequently, a comprehensive internal review of each free data product was conducted to attain in-depth familiarity with the content of the data product. In some cases, communication with individual technical contacts was needed to resolve details that were not readily discernable from the content.

The evaluation methods that were excerpted from the self-assessments and the internal review are presented in Table 1 . This table contains methods from two articles authored by NIST staff members that specifically address critical evaluation of data. Gills et. al. (2001) defined data 
evaluation as "the careful examination of measurement results by experts" and provided three viewpoints for consideration [6]. A comprehensive article by Kramida (2013) presented an extensive list of quantitative critical evaluation methods used in the renowned NIST Atomic Spectra Data Program [7]. Most of the methods in Table 1 were obtained from the article by Kramida. Discussions with SRD experts provided additional methods. Several the methods in Table 1 were reinforced by a panel of SRD experts at the Standard Reference Data Workshop held at NIST on October 17, 2017.

\section{Table 1: Evaluation Methods}

1. Uncertainty assignment

a. Original source

b. NIST, sometimes based on internal consistency of all available data

2. Use of standards

a. Instrument calibration

b. Other standards, e.g., internal standards, wavelength standards

3. Comparisons

a. Agreement between experimental data and data calculated by various methods, e.g., ab initio models, semi-empirical methods

b. Agreement with data obtained by independent measurement methods

c. Agreement with other reliable data

4. Consistency within or between data sets

a. Follow known laws or rules of nature, e.g., positive pressures

b. Obvious errors

c. Self-consistency adjustment, e.g., entire data set

d. Empirically corrected, e.g., known to be off by a certain percentage

e. Re-analysis to maximize consistency of data from various sources

5. Trends
a. Regularity of empirical trends
b. Fit of data to systematic trends
c. Large number of outliers

6. Human element
a. Expert judgment
b. Stature of providers of external data
c. Misprints in publication

7. Data generation
a. Inclusion of metadata
b. Documented procedures
c. Independent variables identified and controlled 


\subsubsection{Data Product Categories}

Information, including the nature of the content, data sources and types, and evaluation methods, were accessed and compiled for each data product. The sources of data were external, internal (generated by NIST), or both. Analysis of this information led to two possible conclusions: (1) a data product was compliant with the SRD definition per the 2017 SRD Update Act and thus retained the SRD label; or (2) a data product was not compliant and was reclassified to a category that better describes the product's content. The following categories were selected for (2):

BC: Bibliographic Collection

DC: Data Compilation

IR: Information Resource

P: Portal to other data products and SRDs

SE: Search Engine for databases that are not critically evaluated or hosted or curated by NIST SW: Software

The category assigned to each data product is presented in Appendix A. For the 75 free data products, it was determined that the majority (49 or 65\%) met the critical evaluation criteria presented in Section 2 and thus retained the SRD label. Figure 4 illustrates the category assignments for the remaining 26 non-SRD data products. Numerical databases that did not meet the criteria were reclassified as Data Compilations. Two of the 26 products were assigned to more than one of the above categories as noted in Appendix A. Fourteen of the data products recommended by the technical contacts to "keep as SRD" were reclassified to other categories.

\subsubsection{Latest Date of New Content}

The "latest date of new content" is an important factor in assessing obsolescence of data products and identifying needs for product updates. Some of the "approximate dates of latest revision" provided by the technical contacts in their self-assessment responses were simply changes to the web interface. In the internal technical review, the latest date of new content for each data product was determined from the content on the data product's web pages. PML data products contain a version history, which greatly facilitated identification of the latest date of new content. For the 75 data products, the latest dates of new content ranged from 1983 to 2017. The number of data products parsed in tenyear increments by this metric are presented in Fig. 5.

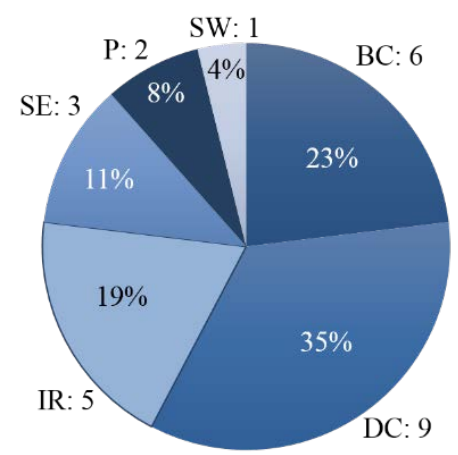

Fig. 4. Distribution of reclassified data products

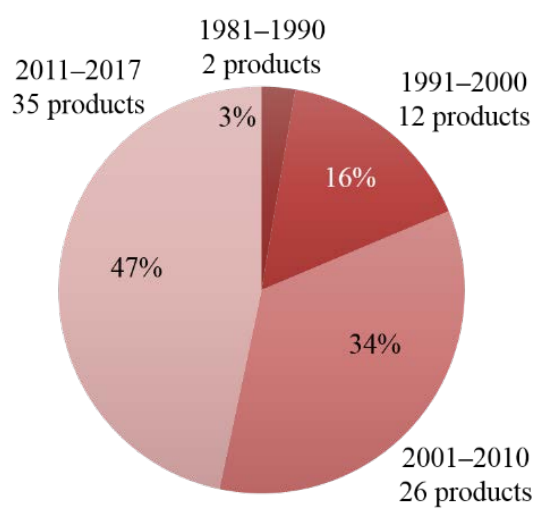

Fig. 5. Latest dates of new content for all free data products 
The latest dates of new content for the 49 data products that retained the SRD label is presented in Fig. 6 in tenyear increments. It is noteworthy that $23 \%$ of the SRDs have content that is more than 17 years old and only 33\% of the SRDs have been updated in the past eight years. Based on further analysis of the individual SRDs, several reasons were determined for content dated 2009 or earlier:

a. The original technical contact left NIST or was assigned to a different project.

b. The topic was no longer a priority for the division or laboratory.

c. The data are essentially invariant due to the fundamental nature of the content, e.g., SRD 142 Energy Levels of Hydrogen and Deuterium.

d. The data are for calibration purposes and are reported to least four significant figures, e.g. SRD 118 Wavenumbers for Calibration of IR Spectrometers.

During the internal review process, defining a category such as "outdated SRD” for SRDs associated with the first two reasons above was considered. However, it was decided that the latest date of new content will be clearly displayed on web interface for each free data product.

\subsubsection{Authoritative Data Products}

During the review process, it was noted that several of the non-SRD data products were designated as "authoritative resources". This term is defined as resources of great significance and impact, widely used, and recognized as a trusted source of information by one or more scientific communities. An example of an authoritative resource is the Short Tandem Repeat DNA Interface Database which has immense value for the forensics community. Approaches to calling out authoritative resources on the NIST data main page [8] are under consideration.

\subsection{External Review Stage}

In this final stage of the SRD review process, subject matter experts from outside NIST will be engaged as peer reviewers for selected SRDs and perhaps other data products. The goal of this activity is to obtain independent and objective information on the use and impact of the selected SRDs.

\section{Conclusions}

The ODI in MML has completed a comprehensive internal technical review of the 75 free SRDs, also referred to as data products. As part of this review, critical evaluation criteria for SRD were developed and evaluation methods used by NIST SRD researchers were compiled. The content of each data product was analyzed with respect to numerous factors. Based on this analysis and the critical evaluation criteria, it was determined that 49 (65\%) of the 75 data products warranted retention of the SRD label. The remaining 26 (35\%) of the data products were reclassified to one or more of six categories that better describe the products' content. The latest date of new content for the data products was tabulated and the implications were analyzed. This review establishes criteria for classifying new data products and will guide the development of new NIST SRD and other data product web pages. 
SRDs are a valued and visible NIST mission-centric product and assuring that the SRD label carries a strong imprimatur is essential to maintain NIST's reputation in the international standards community. Resources should be invested to maintain and expand the SRD Program in support of measurement innovations in science and technology. 


\section{References}

[1] National Bureau of Standards Office of Standard Reference Data (1968) Status Report: National Standard Reference Data System. U.S. Department of Commerce, Washington, D.C., NBS Technical Note 448.

[2] Standard Reference Data Act. Public Law 90-396 [15 U.S.C. 290-290f]; 1968 Jul 11. [accessed 2018 April 6]. https://www.nist.gov/sites/default/files/documents/srd/SRDAct-2.pdf.

[3] H.R. $4284\left(91^{\text {st }}\right)$ : An Act to authorize appropriations to carry out the Standard Reference Data Act. Public Law 91-131; 1969 Dec 01. [accessed 2018 April 6].

https://www.govtrack.us/congress/bills/91/hr4284/text.

[4] S. 3084-American Innovation and Competitiveness Act. Public Law 114-329, Sec. 108. Standard Reference Data Act Update; 2017 Jan 06. [accessed 2018 Jan. 25]. https://www.congress.gov/bill/114th-congress/senate-bill/3084/text.

[5] National Institute of Standards and Technology Standard Reference Data. NIST SRD Catalog; 2012 Mar 15 [updated 2018 Feb 1, accessed 2018 April 6]. https://www.nist.gov/srd/srd-catalog.

[6] Gills TE et. al. (2001) NIST mechanisms for disseminating measurements. J. Res. Natl. Inst. Stand. Technol. 106: 315-340. https://doi.org/10.6028/jres.106.012.

[7] Kramida A (2013) Critical evaluation of data on atomic energy levels, wavelengths, and transition probabilities. Fusion Science and Technology 93:313-323.

https://doi.org/10.13182/FST13-A16437

[8] National Institute of Standards and Technology Services \& Resources. Data. 2016 Mar 15 [updated 2017 Jan 19, accessed 2018 April 6]. https://www.nist.gov/data. 


\section{Appendix A: Free Data Product Categories}

The following table of the 75 free data products in numerical order includes some of the information that was compiled and analyzed in the internal review process. The column labeled CR is the technical contacts' recommended disposition of the SRDs (see page 4). Category assignments based on our analysis are presented in the last two columns; the acronyms in the "Other" column are defined on page 6. Latest date of new content is abbreviated as New Content.

\begin{tabular}{|c|c|c|c|c|c|c|}
\hline \multirow[b]{2}{*}{ SRD } & \multirow[b]{2}{*}{ Database Name } & \multirow[b]{2}{*}{ Lab } & \multirow[b]{2}{*}{ CR } & \multirow[b]{2}{*}{$\begin{array}{l}\text { New } \\
\text { Content }\end{array}$} & \multicolumn{2}{|c|}{ Category } \\
\hline & & & & & SRD & Other \\
\hline $1 C$ & $\begin{array}{l}\text { NIST Peptide Tandem Mass Spectral Libraries } \\
\text { with Search Program }\end{array}$ & MML & 1 & 2012 & $x$ & \\
\hline 8 & XCOM-Photon Cross Sections Database & PML & 1 & 1998 & $x$ & \\
\hline 13 & NIST-JANAF Thermochemical Tables & MML & 2 & 1998 & $\mathrm{x}$ & \\
\hline 17 & NIST Chemical Kinetics Database & MML & 1 & 2016 & & DC \\
\hline 20 & NIST X-ray Photoelectron Spectroscopy Database & MML & 1 & 2012 & $\mathrm{x}$ & \\
\hline 30 & NIST Structural Ceramics Database (SCD) & MML & 1 & 2002 & $\mathrm{x}$ & \\
\hline 40 & $\begin{array}{l}\text { NDRL/NIST Solution Kinetics Database on the } \\
\text { Web }\end{array}$ & MML & 2 & 2002 & $\mathrm{x}$ & \\
\hline 60 & NIST ITS-90 Thermocouple Database & PML & 1 & 1995 & $\mathrm{x}$ & \\
\hline 62 & $\begin{array}{l}\text { NIST High Temp. Superconducting Materials } \\
\text { (HTS) Database }\end{array}$ & MML & 1 & 1997 & $\mathrm{x}$ & \\
\hline 64 & $\begin{array}{l}\text { NIST Electron Elastic-Scattering Cross-Section } \\
\text { Database }\end{array}$ & MML & 1 & 2003 & $x$ & \\
\hline 66 & $\begin{array}{l}\text { X-ray Form Factor, Attenuation, and Scattering } \\
\text { Tables }\end{array}$ & PML & 1 & 2003 & $\mathrm{x}$ & \\
\hline 69 & NIST Chemistry WebBook & MML & 1 & 2018 & $\mathrm{x}$ & \\
\hline 71 & NIST Electron Inelastic-Mean-Free-Path Database & MML & 1 & 1999 & $\mathrm{x}$ & \\
\hline 74 & Thermodynamics of Enzyme-Catalyzed Reactions & MML & 1 & 2007 & $\mathrm{x}$ & \\
\hline 78 & Atomic Spectra Database & PML & 1 & 2018 & $\mathrm{x}$ & \\
\hline
\end{tabular}




\begin{tabular}{|c|c|c|c|c|c|c|}
\hline \multirow[b]{2}{*}{ SRD } & \multirow[b]{2}{*}{ Database Name } & \multirow[b]{2}{*}{ Lab } & \multirow[b]{2}{*}{ CR } & \multirow[b]{2}{*}{$\begin{array}{c}\text { New } \\
\text { Content }\end{array}$} & \multicolumn{2}{|c|}{ Category } \\
\hline & & & & & SRD & Other \\
\hline 81 & $\begin{array}{l}\text { NIST Heat Transmission Properties of Insulating } \\
\text { and Building Materials }\end{array}$ & EL & 1 & 1983 & $x$ & \\
\hline 82 & $\begin{array}{l}\text { NIST Electron Effective-Attenuation-Length } \\
\text { Database }\end{array}$ & MML & 1 & 2009 & $x$ & \\
\hline 101 & $\begin{array}{l}\text { Computational Chemistry Comparison and } \\
\text { Benchmark Database }\end{array}$ & MML & 1 & 2018 & $x$ & \\
\hline 105 & Elemental Data Index (PhysRefData) & PML & 1 & NA & & $P$ \\
\hline 106 & IUPAC-NIST Solubility Database & MML & 1 & 2016 & $x$ & \\
\hline 107 & $\begin{array}{l}\text { Electron-Impact Cross Section for Ionization and } \\
\text { Excitation }\end{array}$ & PML & 1 & 2004 & $\mathrm{x}$ & \\
\hline 108 & Handbook of Basic Atomic Spectroscopic Data & PML & 1 & 2005 & $x$ & \\
\hline 109 & $\begin{array}{l}\text { Atomic Spectral Line Broadening Bibliographic } \\
\text { Database }\end{array}$ & PML & 1 & 2018 & & $\mathrm{BC}$ \\
\hline 110 & $\begin{array}{l}\text { Atomic Transition Probability Bibliographic } \\
\text { Database }\end{array}$ & PML & 1 & 2018 & & $\mathrm{BC}$ \\
\hline 111 & $\begin{array}{l}\text { Ground Levels and Ionization Energies for the } \\
\text { Neutral Atoms }\end{array}$ & PML & 1 & 2013 & $x$ & \\
\hline 112 & Ultraviolet Spectrum of a Platinum Lamp & PML & 1 & 2003 & $x$ & \\
\hline 114 & Diatomic Spectral Database & PML & 1 & 2002 & $x$ & \\
\hline 115 & Hydrocarbon Spectral Database & PML & 1 & 2002 & $x$ & \\
\hline 116 & $\begin{array}{l}\text { Observed Interstellar Molecular Microwave } \\
\text { Transitions }\end{array}$ & PML & 1 & 2009 & $x$ & \\
\hline 117 & Triatomic Spectral Database & PML & 1 & 2002 & $x$ & \\
\hline 118 & $\begin{array}{l}\text { Wavenumbers for Calibration of IR } \\
\text { Spectrometers }\end{array}$ & PML & 4 & 1995 & $x$ & \\
\hline 119 & Photoionization of CO2 (ARPES) & PML & 4 & 2001 & $x$ & \\
\hline 120 & Radionuclide Half-Life Measurements & PML & 1 & 2003 & $x$ & \\
\hline 121 & $\begin{array}{l}\text { CODATA Internationally Recommended } 2014 \\
\text { Values of the Fundamental Physical Constants }\end{array}$ & PML & 3 & 2014 & $x$ & \\
\hline
\end{tabular}




\begin{tabular}{|c|c|c|c|c|c|c|}
\hline & & & \multicolumn{2}{|c|}{ Category } \\
\hline SRD & Database Name & Lab & CR & $\begin{array}{c}\text { New } \\
\text { Content }\end{array}$ & SRD & Other \\
\hline 122 & International System of Units (SI) & PML & 4 & 2000 & & IR \\
\hline 123 & $\begin{array}{l}\text { Fundamental Physical Constants Searchable } \\
\text { Bibliography }\end{array}$ & PML & 3 & 2014 & & $B C$ \\
\hline 124 & $\begin{array}{l}\text { Stopping-Power \& Range Tables for Electrons, } \\
\text { Protons, and Helium Ions }\end{array}$ & PML & 1 & 2017 & $x$ & \\
\hline 125 & $\begin{array}{l}\text { Bibliography of Photon Total Cross Sections } \\
\text { (Attenuation Coefficient) Measurements }\end{array}$ & PML & 3 & 2014 & & $\mathrm{BC}$ \\
\hline 126 & X-Ray Mass Attenuation Coefficients & PML & 1 & 1995 & $x$ & \\
\hline 128 & X-ray Transition Energies Database & PML & 2 & 2003 & $x$ & \\
\hline 130 & Short Tandem Repeat DNA Internet Dataㅡase & MML & 1 & 2018 & & $\begin{array}{l}\mathrm{DC}, \mathrm{IR}, \\
\mathrm{BC}\end{array}$ \\
\hline 131 & Human Mitochondrial Protein Database & MML & 3 & 2007 & & SE \\
\hline 134 & $\begin{array}{l}\text { Database of the Thermophysical Properties of } \\
\text { Gases used in the Semiconductor Industry }\end{array}$ & PML & 1 & 2000 & & DC \\
\hline 137 & $\begin{array}{l}\text { Fracture Toughness / Fracture Energy Data for } \\
\text { Oxide Glasses }\end{array}$ & MML & 1 & 1985 & $x$ & \\
\hline 138 & $\begin{array}{l}\text { Fracture Toughness / Fracture Energy Data for } \\
\text { Ceramics }\end{array}$ & MML & 1 & 1998 & $x$ & \\
\hline 139 & $\begin{array}{l}\text { Phase Diagrams and Computational } \\
\text { Thermodynamics }\end{array}$ & MML & 4 & 1999 & & DC \\
\hline 140 & Statistical Reference Datasets & ITL & 1 & 2003 & $x$ & \\
\hline 141 & $\begin{array}{l}\text { Atomic Reference Data for Electronic Structural } \\
\text { Calculations }\end{array}$ & PML & 1 & 1997 & $x$ & \\
\hline 142 & Energy Levels of Hydrogen and Deuterium & PML & 1 & 2005 & $x$ & \\
\hline 143 & $\begin{array}{l}\text { Potential Energy Surface Database of Group II } \\
\text { Dimer Molecules }\end{array}$ & PML & 4 & 2010 & & DC \\
\hline 144 & $\begin{array}{l}\text { Atomic Weights and Isotopic Compositions with } \\
\text { Relative Masses }\end{array}$ & PML & 4 & 2013 & & DC \\
\hline 145 & $\begin{array}{l}\text { Periodic Table - Atomic Properties of the } \\
\text { Elements }\end{array}$ & PML & 4 & 2017 & & IR \\
\hline 147 & Ionic Liquids Database - ILThermo (V. 2.0) & MML & 1 & 2016 & $x$ & \\
\hline
\end{tabular}




\begin{tabular}{|c|c|c|c|c|c|c|}
\hline \multirow[b]{2}{*}{ SRD } & \multirow[b]{2}{*}{ Database Name } & \multirow[b]{2}{*}{ Lab } & \multirow[b]{2}{*}{ CR } & \multirow[b]{2}{*}{$\begin{array}{l}\text { New } \\
\text { Content }\end{array}$} & \multicolumn{2}{|c|}{ Category } \\
\hline & & & & & SRD & Other \\
\hline 148 & $\begin{array}{l}\text { ChemRate: A Calculational Database for } \\
\text { Unimolecular Reactions }\end{array}$ & MML & 1 & 2011 & & SW \\
\hline 150 & $\begin{array}{l}\text { NIST Property Data Summaries for Advanced } \\
\text { Materials }\end{array}$ & MML & 1 & 2002 & $x$ & \\
\hline 151 & Ceramics WebBook & MML & 1 & NA & & $P$ \\
\hline 152 & Cryogenic Materials Property Database & MML & 4 & 2012 & & DC \\
\hline 153 & Biofuels Database & MML & 3 & 2007 & & SE \\
\hline 154 & $\begin{array}{l}\text { NIST Backscattering-Correction-Factor Database } \\
\text { for Auger Electron Spectroscopy, V. } 1.1\end{array}$ & MML & 1 & 2011 & $\mathrm{x}$ & \\
\hline 155 & Chem-Blast Gateway for PDB Ligands & MML & 1 & 2016 & & SE \\
\hline 156 & Clathrate Hydrate Physical Property Database & MML & 1 & 2009 & $\mathrm{x}$ & \\
\hline 158 & $\begin{array}{l}\text { SAHA Plasma Population Kinetics Modeling } \\
\text { Database }\end{array}$ & PML & 4 & 2003 & & DC \\
\hline 159 & $\begin{array}{l}\text { NLTE4 Plasma Population Kinetics Database of } \\
\text { the 4th Non-LTE Code Comparison Workshop }\end{array}$ & PML & 4 & 2007 & & DC \\
\hline 160 & FLYCHK Database & PML & 1 & 2005 & $\mathrm{x}$ & \\
\hline 161 & Spectrum of Th-Ar Hollow Cathode Lamps & PML & 1 & 2008 & $x$ & \\
\hline 164 & $\begin{array}{l}\text { NIST Database of Cross Sections for Inner-Shell } \\
\text { Ionization by Electron or Positron Impact }\end{array}$ & MML & 1 & 2014 & $x$ & \\
\hline 165 & $\begin{array}{l}\text { NIST Semantics for Biological Data Resource: Cell } \\
\text { Image Database }\end{array}$ & MML & 1 & 2011 & $\mathrm{x}$ & \\
\hline 166 & MEMS Calculator & PML & 1 & 2014 & $\mathrm{x}$ & \\
\hline 167 & $\begin{array}{l}\text { ThermoPlan - Experimental Planning and } \\
\text { Coverage Evaluation Aid for Thermophysical } \\
\text { Property Measurements }\end{array}$ & MML & 1 & 2016 & & $\begin{array}{l}\mathrm{IR}, \mathrm{BC}, \\
\mathrm{DC}\end{array}$ \\
\hline 169 & $\begin{array}{l}\text { Atomic Energy Levels and Spectra Bibliographic } \\
\text { Database }\end{array}$ & PML & 1 & 2017 & & $B C$ \\
\hline 171 & $\begin{array}{l}\text { ThermoLit: NIST Literature Report Builder for } \\
\text { Thermophysical and Thermochemical Property } \\
\text { Measurements }\end{array}$ & $\mathrm{MML}$ & 1 & 2016 & & $B C$ \\
\hline
\end{tabular}




\begin{tabular}{|c|l|c|c|c|c|c|}
\cline { 5 - 7 } & \multicolumn{2}{c|}{ Category } \\
\hline SRD & Database Name & Lab & CR & $\begin{array}{c}\text { New } \\
\text { Content }\end{array}$ & SRD & Other \\
\hline 172 & Synthetic Polymer MALDI Recipes Search Form & MML & 4 & 2012 & & IR \\
\hline 173 & Standard Reference Simulation Website & MML & 1 & 2016 & $X$ & \\
\hline 204 & $\begin{array}{l}\text { NIST Polycyclic Aromatic Hydrocarbon Structure } \\
\text { Index }\end{array}$ & MML & 1 & 2015 & $X$ & \\
\hline & $\begin{array}{l}\text { NIST / ARPA-E Database of Novel and Emerging } \\
\text { Adsorbent Materials }\end{array}$ & MML & 1 & 2016 & & DC \\
\hline
\end{tabular}

